\section{MINUTE LIFE ON OUR SEA-BEACHES. ${ }^{1}$}

$\mathrm{I}$ thinking of a suitable subject on which to address you this evening, it naturally occurred to me that the fellows of the Linnean Society and their friends include both botanists and zoologists, and are all of them, I hope, good field naturalists, who delight in work in the open. So I have decided to talk about

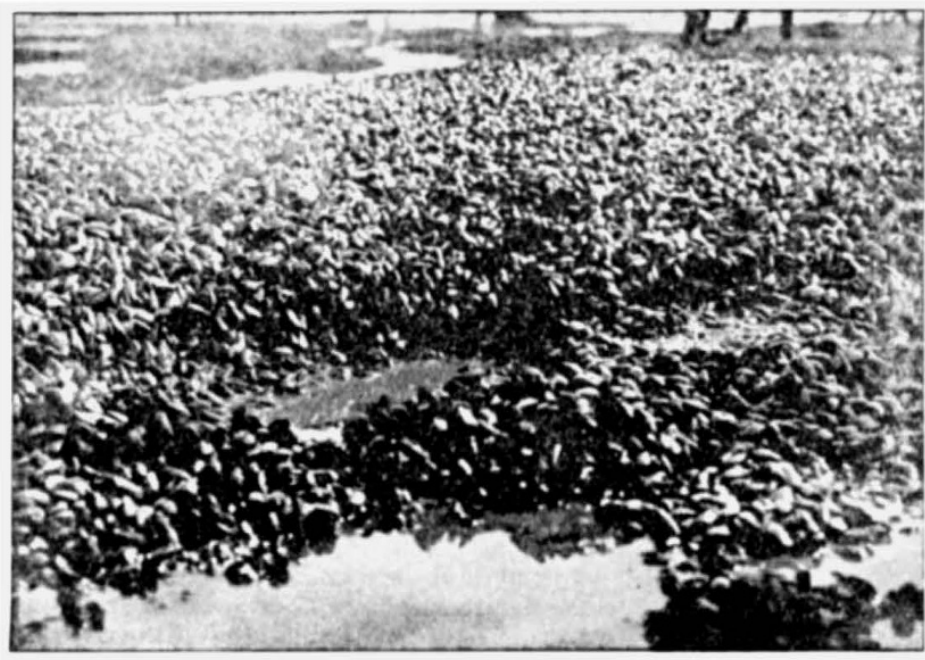

FIG. I.-A Lancashire mussel skear.

what I am coming to regard as a somewhat neglected field of investigation, namely the minute life of our ordinary sea-beaches and the changes which that life undergoes throughout the year. Many biologists are inclined to regard an ordinary sandy beach as a very uninteresting collecting ground, where, they would say, there are but few living things to be found-perhaps some burrowing worms, such as Arenicola, some heart-shaped urchins, like Echinocardium, some lamellibranch molluscs, Solen, Mya and the cockles, and that is about all that most collectors would bring back from such a beach; and we have all heard fishery experts exclaiming at the poverty of such coasts in eloquent words. "Oh, the barren, barren shores which might be cultivated so richly!" is the burden of their cry. There is some truth in it. But if I am able to show that they are not so barren as is supposed, that only makes it the more likely that the beaches might be cultivated with advantage for the benefit of man.

The amount of living things, both plants and animals, that can grow or may be reared in suitable localities between tide marks is astonishing. Let me show you a few photographs exhibiting life in profusion, both in its natural wild state and also under artificial cultivation, as examples of characteristic views on our coasts. Some show patches of the littoral zone near low tide mark, with in some cases huge colonies of the fleshy coral Alcyonium, and numbers of sea-anemones, of worm-tubes, and of zoophytes; in other cases masses of the larger algæ, Fucus and Laminaria; and then again some have the molluscs, Patella, Purpura, and Littorina, covering almost every available inch of the ground. Other more rocky shores, such as Bradda Head at the south end of the Isle of Man, have the stone so closely infested with

1 An address given at the Linnean Society's Reception on October $3^{x}$ by Prof. W. A. Herdman, F. R.S.

NO. 2248 , VOL. 90]
Balanus, the acorn-shell, that for hundreds of yards it looks at low tide, from a distance, as if a broad, uninterrupted horizontal band of white had been painted on the rock, and on going close up to such a cliff one sees that for many yards in succession it is difficult to find a spot of exposed stone on which to put a finger.

Then, as an example of what could be done by cultivation, even of the rudest kind, we may look at these photographs of the mussel skears on some parts of the coast of Lancashire (see Fig. I), where the shellfish soon become so closely crowded that, unless thinned out, they prevent each other's growth by their mutual pressure.

These organisms, however, are all large, common, and well known, while what I desire to bring before you as a neglected field is the presence of minute and little-known organisms which appear in profusion in some localities, at any rate on certain occasions, and are probably of enormous importance in their influence on the life of larger forms, both on the shore and at sea. Probably many, if not all, seashores would show the phenomena I wish to refer to, but the beach which I take as my example is that at Port Erin, in the Isle of Man, where between two rocky sides there is a flat expanse of sand with the usual barren appearance, and the usual burrowing annelids and molluscs.

The sandy beach has a steeper slope in its upper part, and at the base of this, not very far below highwater mark, and just where the damper, flatter, and less stony part of the sand commences, there are found from time to time throughout the greater part of the year larger or smaller greenish-brown patches, sometimes yards in extent, such as most naturalists would declare at a glance to be caused by

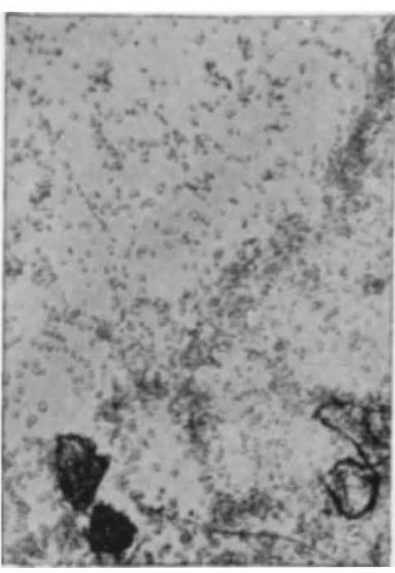

Fı. 2.--Sand-grains and Amphidınium from the beach. Low-power.

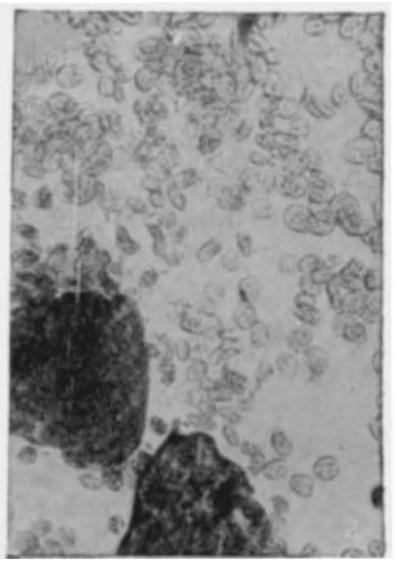

FIG. 3.- $f$ art of Fig. 2 under highpower magnification. accumulations of diatoms-and diatoms we at Port Erin at first supposed them to be. But one day last year on collecting a sample and putting it under the microscope I was astonished to find that the deposit was composed of an enormous quantity of minute, active, flagellate, yellow organisms, evidently belonging to the Dinoflagellata, and related to Peridinium (see Figs. 2 and 3 ). 
This organism proved on further investigation to by diatoms for a few days, and in the latter part of be Amphidinium operculatum, Clap. and Lachm., April, 1912, the alternation took place no fewer than which had never before been found in British seas, four times, ending with a couple of weeks in May, and very rarely anywhere else. And yet here it was when neither organism was present. Amphidinium

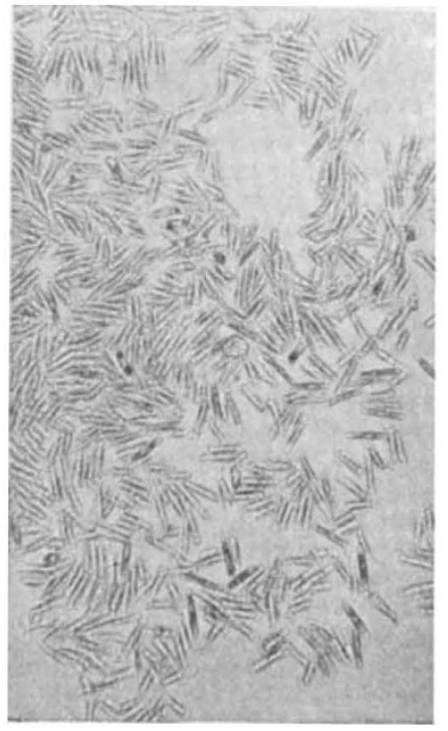

FıG. 4.-Navicula digito-radiata.

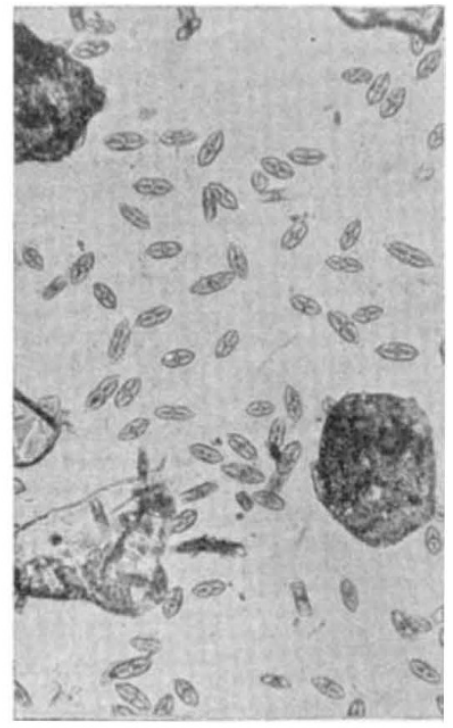

Fig. 5.-Navicula amphislacna (?). reappeared on May $1 \overline{5}$, and was present more or less during the greater part of the summer, except in the drier intervals of July and August, when it was absent. From September 14 onwards it has again been present in laryer or smaller patches, and I have examined living samples sent from Port Erin, up to the last day of October; but, curiously enough, the individuals in these recent gatherings differ considerably in shape, size, and some other minor points from the Amphidinium operculatum we had been examining in such quantity at Port Erin during the previous year.

I am not of opinion as yet that this difference indicates more than a form of the same species-possibly scasonal or due to age or nutrition, or some other environmental influence; and the variation does not affect the broad phenomenon of the striking alternation of the two very different linds of organisms, diatoms and Dinoflagellates, in vast quantity. Although it may not be possible yet to give any detailed explanation, the facts seem to point to the probability that the cause of the phenomenon is a physiological one,

in vast amount for weeks at a time ${ }^{2}$; and I am inclined to think it may be abundant on other beaches also. Several naturalists have told me since I mentioned this matter to the Linnean Society last year that they are convinced that they have previously seen Amphidinium patches on the shore, and had taken them for diatoms. But one of the most extraordinary points about the occurrence of this little Dinoflagellate is that it seems to alternate in time on the beach with almost pure cultures of certain common diatoms, such as Navicula amphisbaena, Bory, and N. digito-radiata, Greg. (see Figs. 4 and 5).

During $191 \mathrm{I}$ the historv of these coloured patches on Port Erin beach was as follows :-

April 7 to May 1.-Amphidinium and a few di a to m s (Navicula).

June 3 to July 22.-Diatoms (some $\mathrm{Navicula}$, others Pleurosigma).

September 9 and 10.-- $\Lambda$ mphidinium in abundance; diatoms absent.

September 16 to $18 .-$ Diatoms (Navicula).

October 2 to $26 .-$ Amphidinium in a bund an ce : diatoms absent.

October 28 to November I.-No Amphidinium present.

November 2.-Amphidinium (three small patches).

During the remainder of the winter no patches were found, but by the beginning of April Amphidinium had reappeared in force and monopolised the beach for a couple of weeks. It was then replaced 2 See Journ. I.inn. Soc., vol. xxxii., No. 212, October, $191 \mathrm{r}$. NO. 2248, VOL. 90]

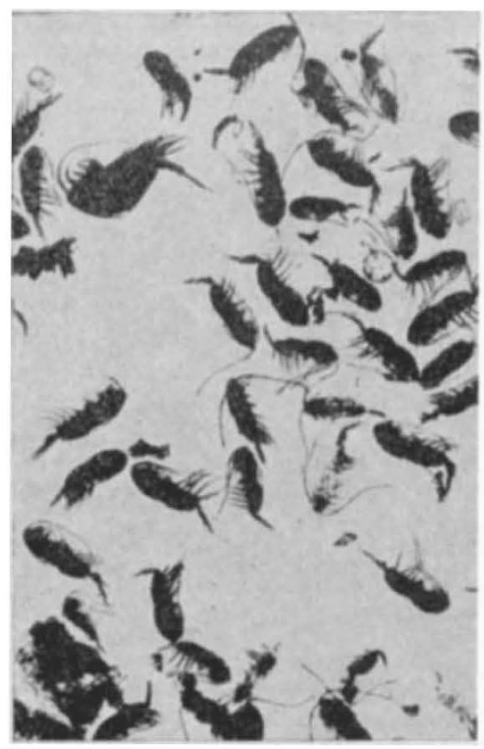

Fic. 6.-Copepod zoo-plankton from summer and that the explanation may consist in showing that each organism in turn in its metabolism exhausts or alters some essential constituent of the environment, so as to prevent its own continued existence, in quantity, at that spot, but leaves the ground suitable, or even favourable, to the physiological needs of the other set of competing organisms.

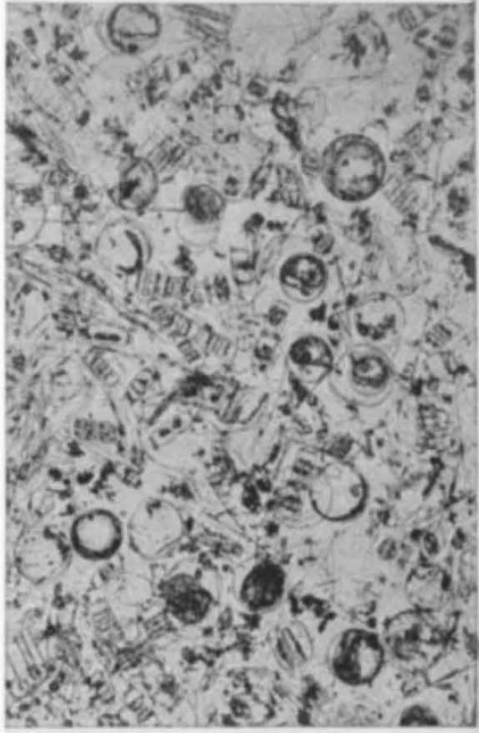

F1G. 7--Diatom phyto-plankton from spring

$$
\begin{aligned}
& \text { gatherings. } \\
& \text { I owe all the photomicrographs to the skill of my friend Mr. Edwin Thompson. }
\end{aligned}
$$

Possibly we have a similar phenomenon on a more extended scale in the well-known seasonal variations of the plankton of the open sea, where during spring and summer the main constituent groups of organisms are Diatoms, Dinoflagellates, and Copepoda, succeeding one another in that order. (Figs. 6 and 7 show 
a spring phytoplankton and a summer zooplankton gathering.). Prof. Benjamin Moore has recently foun ${ }^{3}$ a noteworthy change in the chemical reaction of the sea water round our coasts at different seasons of the year, no doubt in co-relation with the development of the plankton organisms. In spring (April) the water, not only on the shore, but out at sea, is acid to phenolphthalein, while in summer (August) it is distinctly alkaline to the same indicator. This change signifies an enormous conversion of carbon in the inorganic into carbon in organic form, a turn-over of colossal extent amounting to between 20,000 and 30,000 tons of carbon per cubic mile of sea water, or, if we thinl of the carbon as being in the bodies of living organisms, then the weight of these organisms will amount to about ten times that quantity of carbon in the cubic mile--or, if we imagine it occupying the deepest part of the Irish Channel, say, 300,000 tons of organisms per strip of water ten miles long by one mile broad and eighty-eight fathoms deep, all supplied with their necessary carbon from the carbon dioxide present in the sea water in spring.

Thus we can be led on from the simple observation of minute organisms on the beach to some of the greatest problems in the metabolism of the ocean; but the naturalist investigator need not necessarily venture out to sea in his quest. There is plenty of useful work to be done on the beach in carefully examining with the microscope the various deposits, such as sand and mud, found between tide marks, not once for all, but periodically, so as to determine the nature of the minute animals and plants, their relative abundance, and their variations, seasonal or otherwise, in quantity and character throughout the year. We know that some of these organisms, although individually insignificant, may exist in such quantities as to discolour the sands or the sea water, and even give rise to plagues amongst shellfish and other more directlv valuable animals. Invasions of this kind, due to Dinoflagellata closely allied to our Amphidinium, are known to have appeared in America and in Australia, and possibly elsewhere. It is work worthy of the best endeavours of some of the younger botanists and zoologists of the Linnean Society, who have ready access to the coast, to try to extend our knowledge of the range and life conditions of some of those remarkable organisms-organisms which not only present scientific problems to the field naturalist, the cytologist, the experimental biologist, and biochemist, but, moreover, may well, from their vast numbers and sudden changes, have a profound effect upon the metabolism of the ocean, and so upon the prosperity of sea-fisheries.

\section{THE UNIVERSITY OF BRISTOL IN RELATION TO AGRICULTURE.}

THE University of Bristol, the youngest of our universities, has made it evident that it intends to play an active part in the development of agricultural education and research. Some two years ago the University associated with itself the Royal Agricultural College, Cirencester, for purposes of higher education in agriculture, and arrangements for the granting of degrees in that subject are now being completed.

The Board of Agriculture and Fisheries has recently notified its intention of making an annual grant of $500 l$. to the college to enable it to provide for research on questions relating to forestry for the west of England area. 3 In the course of a Percy-Sladen Trust research upon the nutrition of
maine animals, the detailed results of which will be published at an early vat?.

NO. 2248, VOL. 90]
The University has also recently associated with itself the National Fruit and Cider Institute, which was established at Long Ashton, near Bristol, in 1903, to carry on investigations on fruit culture and cidermaking. This institution has been supported since its establishment by annual grants from the Board of Agriculture and Fisheries, the county councils of Devon, Gloucester, Hereford, Monmouth, Somerset, and Worcester, and the Bath and West of England Agricultural Society. Its association with the University is the result of an offer on the part of the Board of Agriculture and Fisheries to the latter of an annual grant approximating to $2500 l$. to provide for the establishment of one of the agricultural research institutions contemplated by the Board in connection with the grant from the Development Fund available for the promotion of agricultural research.

The special subject of research allotted to Bristol is that of fruit-growing, including the practical treatment of plant diseases. The offer of the Board was conditional on the National Fruit and Cider Institute being made the centre at which the work was to be carried on. In connection with the scheme a capital expenditure of $10,000 l$. has been estimated to be necessary. Of this sum the Development Commissioners intimated their willingness to provide 50 per cent., provided that the remaining half was raised locally. Largely owing to the efforts of the Rt. Hon. Henry Hobhouse, chairman of the Somerset County Council, the necessary money has been subscribed. The expenditure is required for the purchase of land and the erection and equipment of laboratories and other buildings at Long Ashton. A department of agricultural and horticultural research has thus been created, Mr. B. T. P. Barker, director of the National Fruit and Cider Institute, being appointed head of the department and professor of agricultural biology in the University. Towards the upkeep of the department the University is contributing an annual sum of $300 l$., the income of a gift from the late Lord Winterstoke for the purpose of agricultural research; and the income from other sources, including county council grants, is about ${ }^{1} 500 l$.

The department of chemistry in the University is also taking part in the work. In the biochemical laboratory, investigations on the tannins of cider are proceeding in connection with the fruit research work. A special grant from the Development Fund for the continuation of investigations on the chemistry of Cheddar cheese, which have been carried out during the past two years by Dr. Nierenstein, has been promised. This work was begun in the first place at the request of the Somerset County Council, a grant for the purpose being given by that body.

The Board of Agriculture and Fisheries also proposes to make the University the centre for a group of the western counties in connection with its scheme for the provision of technical advice to farmers. The group will probably include Gloucester, Hereford, Somerset, Wiltshire, and Worcester, and possibly one or two other adjoining counties for special purposes. An annual sum of roool. is provided by the Board for this work. Under this scheme investigations on problems of local agricultural importance will be undertaken. In this connection reference may be made to the work on the "teart" or scouring land of Somerset, which has already been conducted by Mr. C. T. Gimingham for the past two years.

The following appointments to the staff of the Department of Agricultural and Horticultural Research have already been made:-Mr. A. H. Lees as plant pathologist, Mr. C. T. Gimingham as agricultural chemist, and Mr. Otto Grove, for some time assistant to Dr. Alf. Jörgensen, of Copenhagen, as 